\title{
Investigation of the visual appearance of different skirt styles and materials during the fitting simulation with Lectra Modaris
}

\author{
Tibifez Hailu Nechno ${ }^{1, *}$, Yordan Kyosev ${ }^{2}$, Mulat Alubel ${ }^{1,3}$, Sybille Krzywinski ${ }^{2}$ \\ ${ }^{1}$ Ethiopian Institute of Textile and Fashion Technology (EiTEX), Bahir Dar, Ethiopia \\ 2 Institut für Textilmaschinen und Textile Hochleistungswerkstofftechnik (ITM), Technische Universität Dresden, \\ Dresden, Germany \\ ${ }^{3}$ Ecole Nationale Supérieure des Arts et Industries Textiles: Roubaix, Nord-Pas-de-Calais, France \\ ${ }^{*}$ Corresponding author E-mail address: tibeb33@gmail.com
}

\section{INFO}

CDAPT, ISSN 2701-939X

Peer reviewed article

2021, Vol. 2, No. 2, pp. 141-150

DOI 10.25367/cdatp.2021.2.p141-150

Received: 20 July 2020

Accepted: 05 December 2021

Available online: 9 December 2021

\begin{abstract}
This paper examines the influence of different fabric types and material properties on the visual appearance of three types of skirt styles using numerical simulation. The purpose of the simulation is to present and analyze the appearance of virtual garments, create the best-fitting pattern pieces, and choose the appropriate fabric type based on the multiple clothing styles to achieve the intended design. The results show that when the type of fabric changes without changing the clothing style and on the other hand the style changes without changing the type of material, the appearance of the garment changes and the effect can be clearly seen with the 3D comparison result. These changes should be taken into account when choosing the right fabric for different styles.
\end{abstract}

(C) 2021 The authors. Published by CDAPT. This is an open access article under the CC BY-NC-ND license https://creativecommons.org/licenses/ peer-review under responsibility of the scientific committee of the CDAPT.

(C) 2021 CDAPT. All rights reserved.

\section{Introduction}

Clothing is always used to describe differences in social status, age, wealth and gender. However, the appearance of a garment is influenced by material, the pattern and the human wearing it. The material is specified by the quality of the fabrics and its drape behavior. The pattern generally is specified by the $2 \mathrm{D}$ construction and partially by the garment manufacturing process [1, 2].

The modern 3D CAD systems for clothing development are able to perform virtual fitting and simulate the visual appearance of the fabrics for more than ten years [3]. The garment is constructed normally as 2D pattern, modified and then the quality of its fit is evaluated on human 3D models [4]. For this purpose, distance ease, wearing silhouette and distribution of strain in a virtual garment are analyzed without producing the garment. One of the complex questions still remaining open is how accurate the virtual 
simulation is which is used for this evaluation. Its evaluation requires larger numbers of simulations and scans. This paper has the goal to check not the accuracy, but the sensitivity of the appearance of a skirt to the material parameters and the style.

\section{State of the art}

Modern 3D clothing CAD systems include physical based fabric simulation, virtual fitting, 3D costume design technology, and 2D and 3D mutual conversion technology [5]. With the application of 3D virtual clothing prototyping, the 2D patterns of the clothing can be placed and draped on the virtual human body. When the virtual prototyping is accurate, the garment fitted to the body model reflects and combines characteristics of the clothing style, the garment pattern design, the virtual body model, and the mechanical properties of textiles [6]. The success of 3D virtual garment prototyping programs depends heavily on the definition of the material properties used in the program. Nowadays there are several 3D CAD software packages for clothing on the market: Modaris 3D Fit by Lectra is one of the 3D virtual prototyping solutions, which links 2D patterns, fabric information and 3D virtual models together; Assyst Vidya connects well with 2D pattern development Assyst CAD [7]. Several recent products like CLO3D and MarvelousDesigner of CLO Virtual Fashion Inc. concentrate on simplified user interfaces. Users can check silhouettes of garments and understand the feelings about the final product without making physical samples, and they can directly simulate different 2D patterns. Changing colors, textures and fabric materials can shorten the time for sample preparation [8]. Actually for the physical testing of samples for CLO3D, a separated testing kit is required.

OptiTex is another fabric simulation software for 3D draping and visualization of garments and is based on 2D CAD patterns and real fabric features. In this software, the user can customize different mannequins according to their preferences. Moreover, the designer can see all the cutting details and check the fit on the virtual fitting model in static or dynamic positions [9].

VStitcherTM from Browzwear software can convert 2D patterns into 3D virtual garments, and the virtual models can be customized according to customers' needs [10]. This software is coupled with pattern drafting, grading and marking software. It integrates excellently with Grafis, which provides a parameter based pattern development tool with large number of clothing construction systems.

The PAD system is visualization software that can be used to create virtual 3D garments from 2D pattern pieces. It includes a fabric simulation tool and texture mapping tools that allow users to simulate fabrics, apply colors, textures and prints. The software also allows the user to adjust fabric properties and see the effects on the drape of the garment [3].

Users can create virtual 3D prototypes of garments based on 2D patterns and fabric properties on the virtual models to view a garment from any angle in a static or dynamic pose and create dynamic storyboards for presentation purposes using the eFit SimulatorTM software. The software also enables digital prototype models that can be sent by e-mail around the world, allowing designers to perform a "virtual fitting" online and in real time [11,12]. Other products such as Gemini and Gerber became part of Lectra and allow users asking which of these products will remain in the near future on the market.

One of the complex questions of all 3D clothing programs is the accuracy of the drape simulation, based on the material properties of the fabrics. Modaris provides a broad library of more than 120 materials along with their mechanical properties, which are tested and prepared and in this way ensure correct simulations. The software also allows the designer entering new fabric properties to view different drape [13], but then the user is responsible for the correct measurement, too. The same options - large library and the possibility to insert new samples with correct material parameters which the user obtained during standard testing - are provided in Assyst Vidya, too. Despite of this, some research institutions try to 
motivate software companies to use unified format for the material data, as until now each CAD software requires different values, based on different testing procedures and stored in different formats. Principally, engineers with good mechanics knowledge are able to re-compute these values [14], but the solvers in the CAD programs remain closed and hidden and the reproducibility of the drape results remains not enough investigated.

Generating and importing avatars is another important feature, which is required for evaluation of the clothing fit. Most of the software packages allow import of externally created avatars. An example of creating pregnant avatars using blender and importing in Lectra Modaris is demonstrated in [15]. The avatars and the CAD software allow as well investigation of body temperature and additional comfort related parameters [16].

3D clothing simulation software has many advantages, however, there are also some limitations, to name just a few: mechanical simulation, collision detection, geometric modeling, interactivity and others are difficult to simulate as real properties. For example, how a fabric responds to folds, creases, tears, and other conditions is the result of the many properties that make up a given fabric. Even more important is how a fabric responds to its environment, with certain fabrics responding very differently, such as how a fabric looks and stretches in the wind and in different lighting conditions. The garment itself must also adapt to the shape and movements of the human body. These properties must therefore be taken into account when developing the right fabric simulation $[11,17]$.

The fit of a garment depends not only on the manufacturing process, but also on the mechanical and structural properties of the chosen fabric. The waveform of clothing depends on the mechanical properties of the material. Change in material type has a greater impact on the waveform of clothing than change in size [18].

Garment pressure and garment fit are affected by body shape, mechanical properties of the fabric, and the style of the garment [19]. Several garments are used as well for correction of the postures of human bodies [20]. Rödel et al. [21] confirm that the stretchability of fabrics is an important mechanical parameter for close-fitting garments. The fit of the garment and the ease of body movement are very much related to the stretchability and resilience of fabrics.

3D technology can reduce or eliminate costly sample making and fitting. However, there is no more systematic study on 3D clothing simulation for the analysis of clothing style and fabric type, especially considering the fabric properties. So the aim of this paper is to study the influence of different fabric types for different skirt styles to represent and analyze the appearance of virtual garments, create the most suitable patterns and select appropriate fabric types based on the different skirt styles to achieve the intended design using "Modaris (Lectra) Software".

\section{Materials and methods}

The skirt pattern was created using Lectra Modaris software. First, a basic skirt was created with two darts in the front waist and two darts in the back, as shown in Figure 1.

This style was modified to create a flared skirt (Fig. 2a) and a bell-shaped skirt (Fig. 2b) as well as a straight or rectangular shape (the skirt hangs straight from the hip line to the hem) (Figure $2 \mathrm{c}$ ). After creating these skirt variations, the cuts were sewn in the virtual plane to verify the 3D fit. A standard mannequin was used for the current evaluation fit of the garment with the different materials (Fig. $2 \mathrm{~d}$ ). The two-dimensional pattern for this study was created for a size 38 woman with body measurements of $70 \mathrm{~cm}$ at the waist, $101 \mathrm{~cm}$ at the full hip, and $15 \mathrm{~cm}$ from the waist to the hip. 

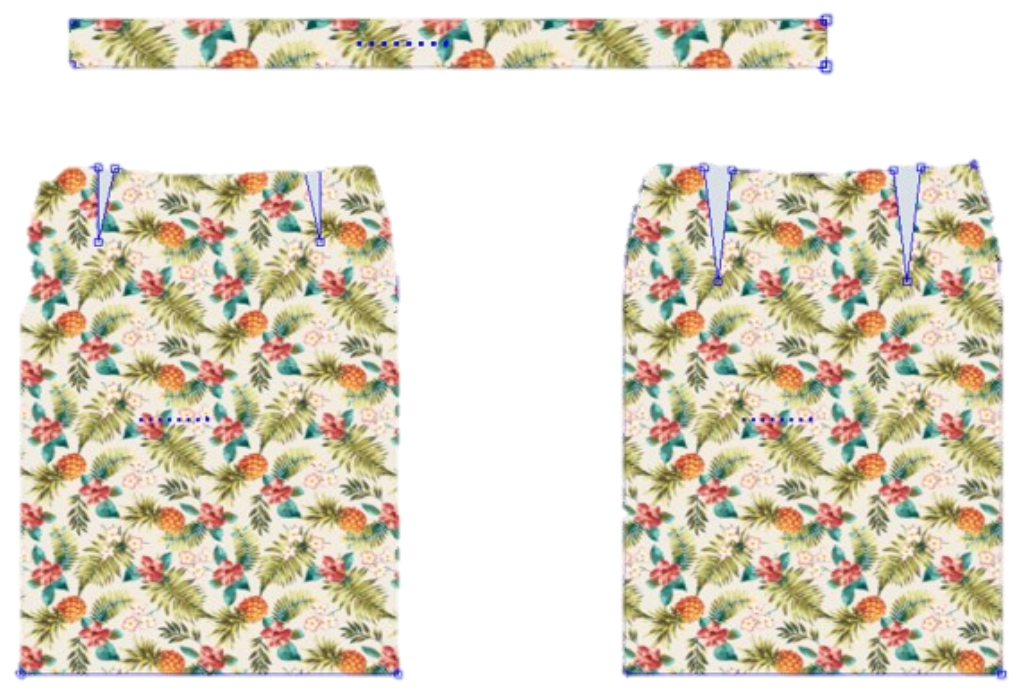

Figure 1 First basic skirt pattern in $2 D$ form

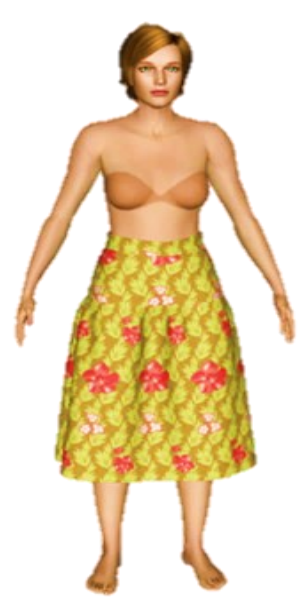

a

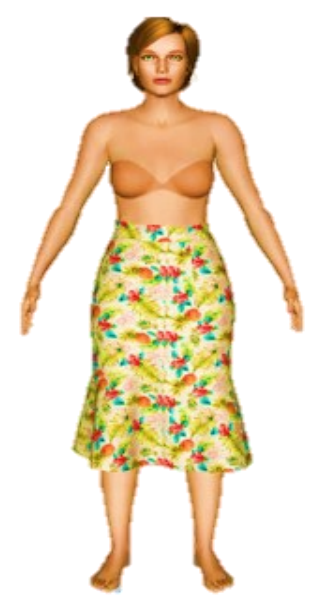

$\mathrm{b}$

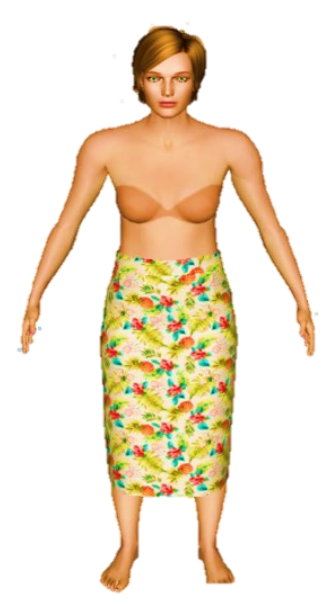

C

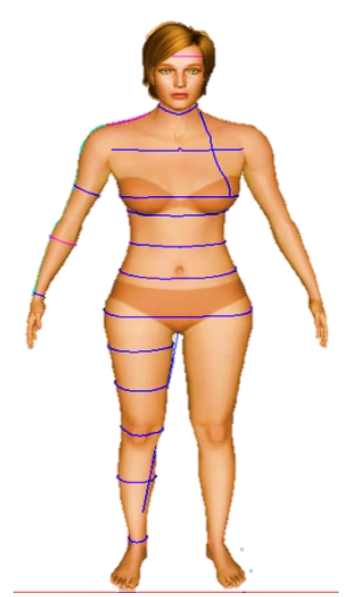

d

Figure 2 (a) Flared skirt; (b) bell-shape; (c) straight; (d) virtual mannequin size 38

The three types of skirts are simulated for six different fabrics, whose main properties are given in Table 1. These are produced of cotton elastane, polyester satin, felting, and linen with silk, cotton voile, and Botany wool serge fabrics and are all randomly selected from the fabrics which are available in the Swatch Book of Lectra [22]. This book contains real samples, so that the user can touch them, and at the same time all their properties for correct draping simulation within the Lectra Modaris V8 software are available in the system.

Elastane fabric has great stretch and recovery properties. Polyester satin fabric is a smooth, shiny fabric with a satin weave and $100 \%$ polyester fibers. Felting fabric is a non-woven fabric that is manufactured by matting and compressing fibers together to form the structure of the fabric. For linen with silk, the strength of both threads makes this fabric durable and abrasion resistant. The silk fiber also gives the linen more softness. Cotton voile, voile made of $100 \%$ cotton or a blend of cotton and linen, allows air to pass through and provides comfort. Because of its fine texture, voile can also be used to hem clothing. Botany wool serge wool is marketed under the name Botany wool to indicate that the wool comes from Botany Bay. The term is reminiscent of knitwear made from very fine wool and has its own special labeling. All these different fiber types provide different appearances and properties of the products. The question in the current study is if and which influence on the appearance can be detected using the 3D simulation capabilities of the Lectra Modaris software. 
Table 1 Mechanical characteristic of tested fabrics

\begin{tabular}{|c|c|c|c|c|c|c|c|c|}
\hline \multirow[t]{3}{*}{ Fabric type } & \multicolumn{2}{|c|}{$\begin{array}{l}\text { General } \\
\text { information }\end{array}$} & \multicolumn{6}{|c|}{ Mechanical properties } \\
\hline & \multirow[t]{2}{*}{$\begin{array}{l}\text { Density } \\
\left(\mathrm{g} / \mathrm{m}^{2}\right)\end{array}$} & \multirow[t]{2}{*}{$\begin{array}{l}\text { Thickness } \\
(\mathrm{mm})\end{array}$} & \multicolumn{2}{|c|}{$\begin{array}{l}\text { Bending resistance } \\
\mathrm{B}(1 \mathrm{e}-6 \mathrm{Nm})\end{array}$} & \multicolumn{2}{|c|}{$\begin{array}{l}\text { Shearing } \\
\text { resistance } G(\mathrm{~N} / \mathrm{m})\end{array}$} & \multicolumn{2}{|c|}{$\begin{array}{l}\text { Tensile Resistance } \\
\text { E100 (\%) }\end{array}$} \\
\hline & & & Warp & Weft & Warp & Weft & Warp & Weft \\
\hline $\begin{array}{l}\text { Polyester } \\
\text { satin }\end{array}$ & 159 & 0.2 & 5.56 & 4.52 & 0.59 & 0.59 & 2.14 & 4.16 \\
\hline Cotton voile & 164 & 0.3 & 5.74 & 4.67 & 4.36 & 4.36 & 2.00 & 3.89 \\
\hline $\begin{array}{l}\text { Botany wool } \\
\text { serge }\end{array}$ & 199 & 0.5 & 8.45 & 4.03 & 7.46 & 7.46 & 3.01 & 6.45 \\
\hline $\begin{array}{l}\text { Cotton } \\
\text { elastane }\end{array}$ & 139 & 0.5 & 21.29 & 0.28 & 7.26 & 7.26 & 16.85 & 27.78 \\
\hline Felting & 166 & 0.9 & 73.80 & 46.47 & 96.88 & 96.88 & 3.83 & 8.00 \\
\hline $\begin{array}{l}\text { Linen with } \\
\text { silk }\end{array}$ & 196 & 0.4 & 87.14 & 10.89 & 1.59 & 1.59 & 0.91 & 1.80 \\
\hline
\end{tabular}

For the analysis of the differences between the results with different fabrics, the simulated geometries are analyzed with Geomagic Qualify software. It can compare the meshes and provide statistical data about the distance between different 3D objects.

\section{Results and discussions}

An overview of all simulated skirts with the three styles and six materials is presented in Figure 3.

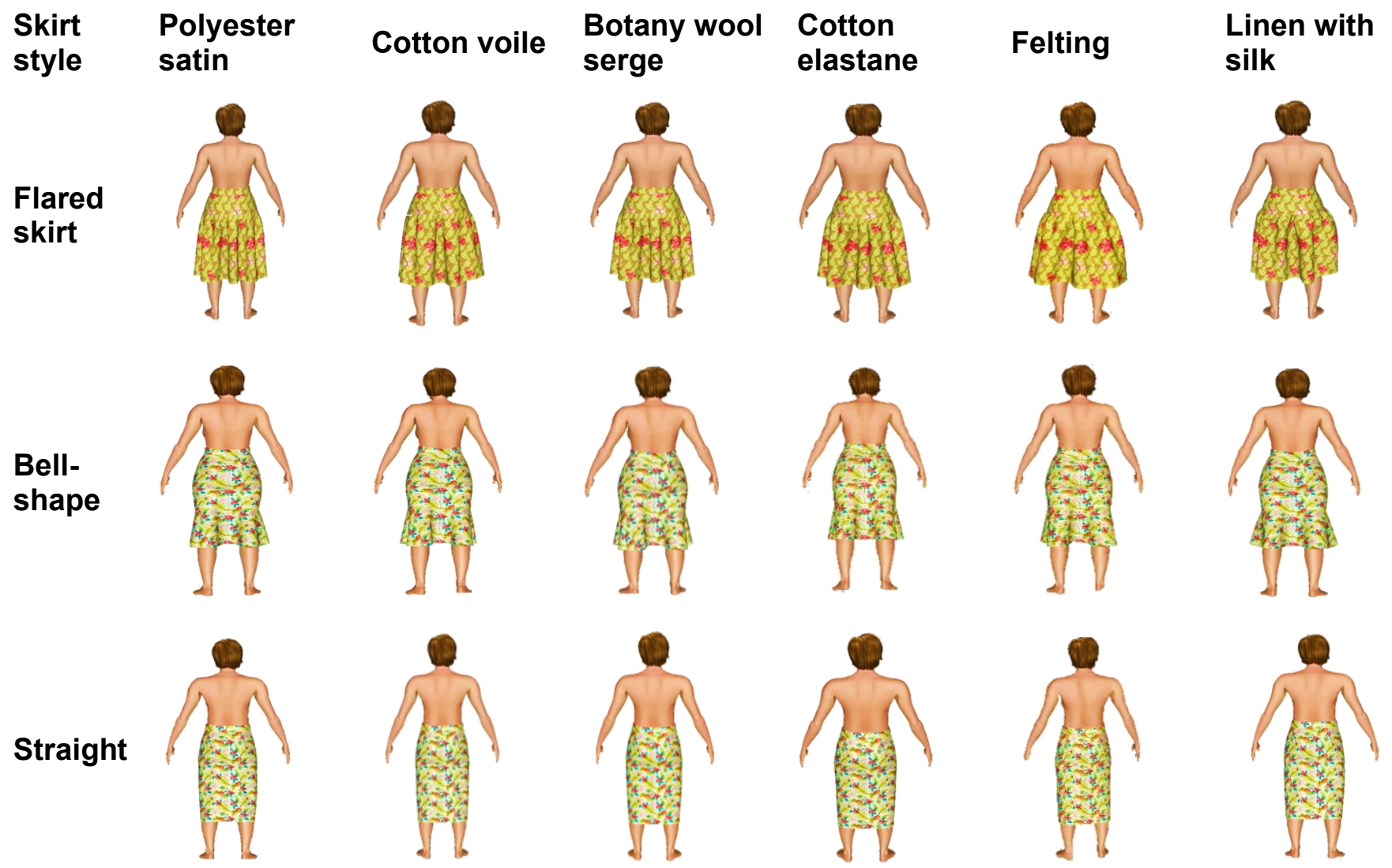

Figure 3. Simulated skirts made of the six different fabrics in three styles in Lectra Modaris software

During the 3D comparison with the geometric quality software, different views (front, back and side) are created both for different fabric types for the same skirt style (see table rows) and for the same fabric for 
different skirt styles (see table columns). The views visualize the distance between the avatar and the simulated clothing in the current material and silhouette. Green indicates areas that fit normally without distance to the body. The light and dark blue colors visualize negative distances to the body. These are areas where the clothing actually has to penetrate in the body, which is the result of the discrete contact detection of the simulation software. Since both human body and cloth are represented by a given number of vertices, the meshes can penetrate in some areas, but this is based on the discretization for the numerical simulation. In reality it means, that this part of the clothing will have higher pressure on the body. The yellow and red colors visualize the positive distances from the skirt to the body.

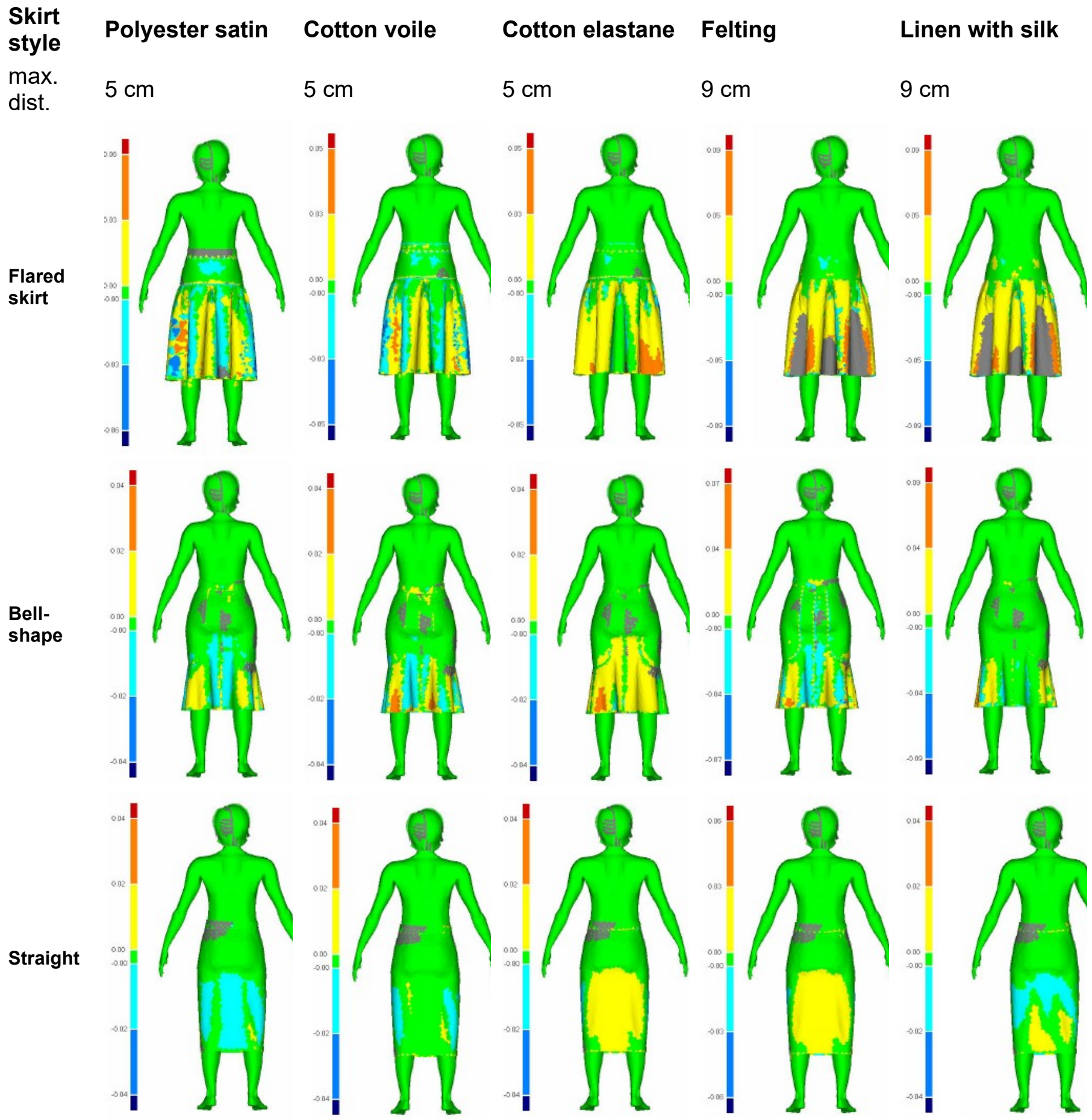

Figure 4. Distance between skirt and avatar - back view

Comparing the distances, represented by the color scales in the 3D results (Figure 4, 5 and 6 ), it can be seen that the style of the skirt significantly influences the appearance, but changes of the physical 
properties are mainly recognized for the materials with higher mass per unit area and higher bending rigidity, i.e. felting and linen/silk. The skirts with these heavier materials show $4 \mathrm{~cm}$ larger deviations in the distance to the body compared to the lighter and softer materials, but the principal appearance is not significantly different.

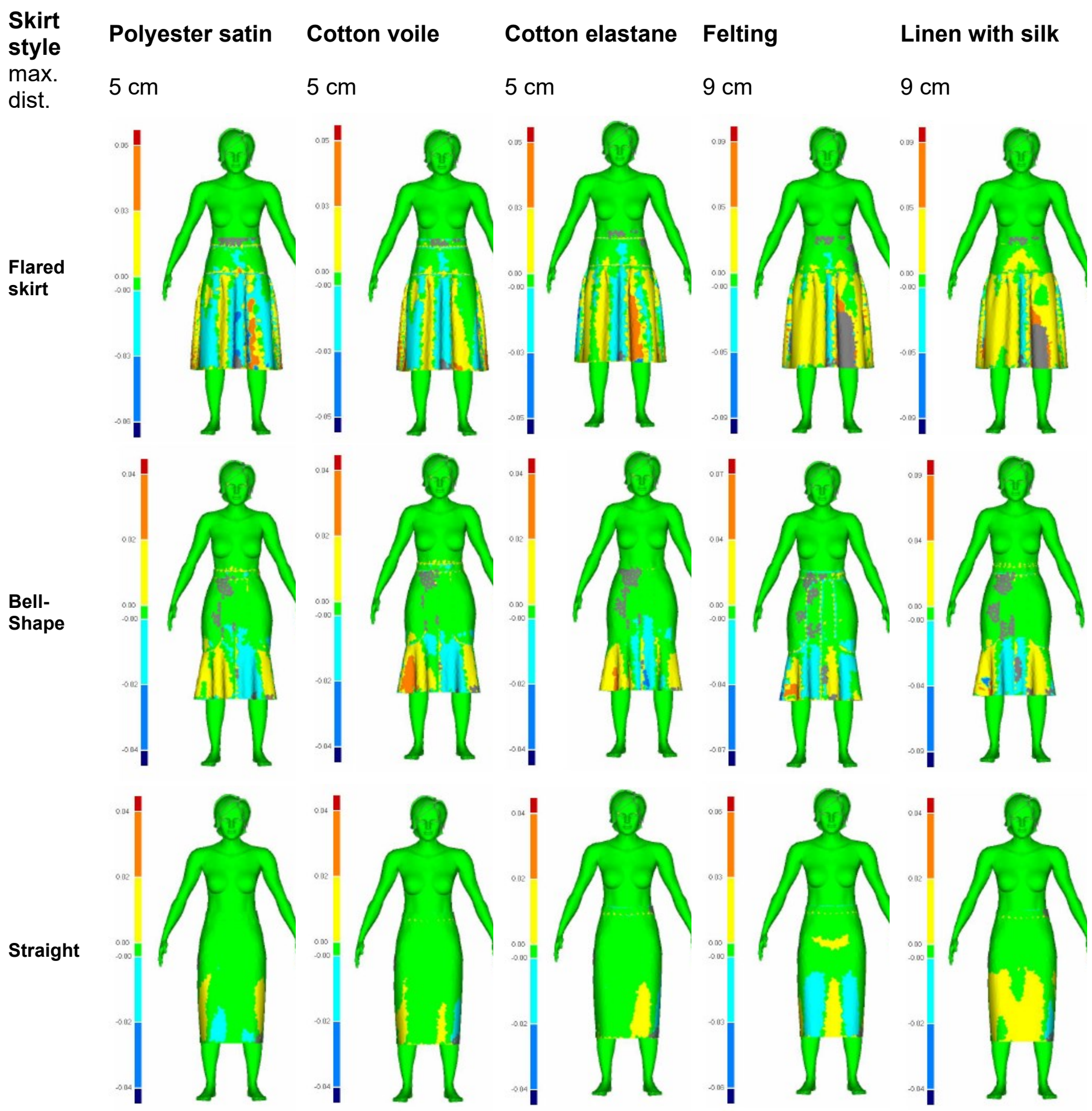

Figure 5. Distance between skirt and avatar - front view

Analyzing again the material data for mass per unit area and bending rigidity (Fig. 7), it can be seen that actually all selected materials are in a relatively close range, as usual for this application, but the heavier and rigid materials fall with larger distances to the body. A relation to the shear modulus is not recognized, despite of that it determines the drape behavior, too. 


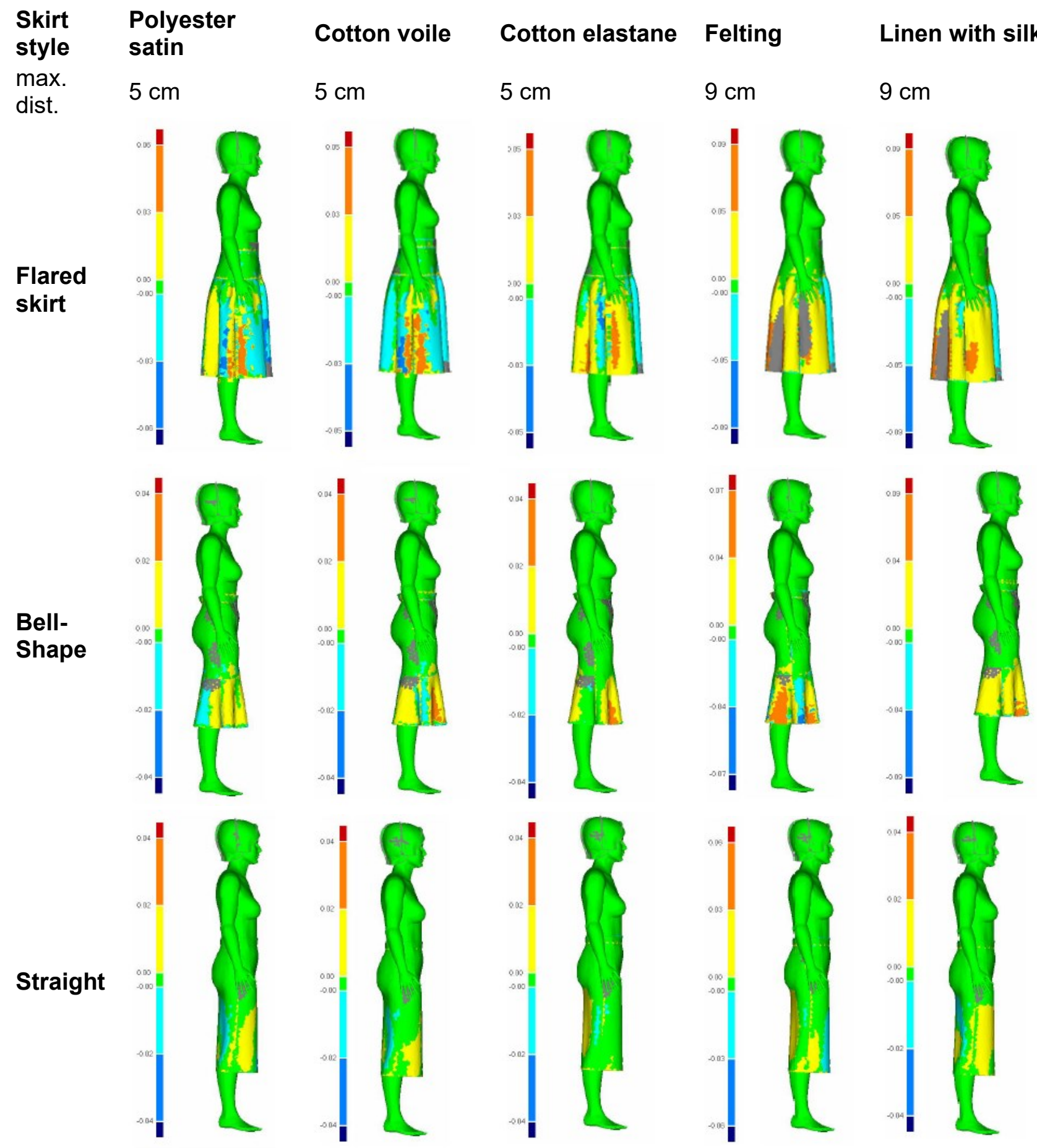

Figure 6. Distance between skirt and avatar - side view

The main reason for absence of significant difference in the simulation between the materials lies most probably on their selection. Despite the different materials and their properties, they were selected based on the feeling of the authors that they seemed suitable for skirt applications. Thus they can be expected to have similar behavior. In this regard, an important conclusion is that samples with mass per unit area in the range between 130 and $200 \mathrm{~g} / \mathrm{m}^{2}$ in combination with bending rigidity under $20 \cdot 10^{-6} \mathrm{Nm}$ and shear resistance lower than $10 \mathrm{~N} / \mathrm{m}$ will produce identical drape appearance. Increasing the bending rigidity over $50 \cdot 10^{-6} \mathrm{Nm}$ produces slightly stiffer appearance, but does not change significantly the appearance 
of the style, defined by the pattern. For these ranges of parameters for the investigated styles the static drape behavior remains identical.

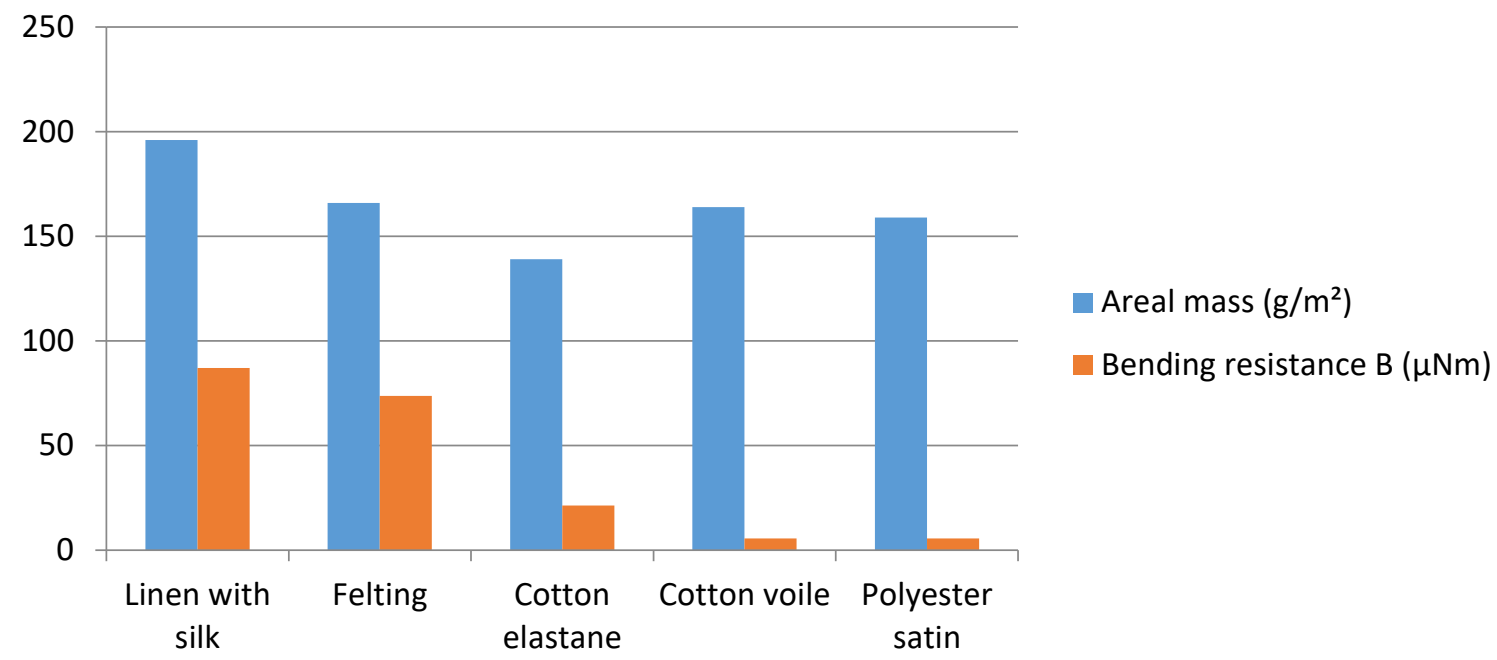

Figure 7. Comparison of the material properties of the fabrics for the skirt

\section{Conclusions}

The developed three styles of skirts, simulated for six different materials, demonstrate that visual appearance of the fabrics remains identical, if the mechanical properties of the fabrics are in the usual range of fabrics for skirts. All samples with mass per unit area in the range between 130 and $200 \mathrm{~g} / \mathrm{m}^{2}$ in combination with bending rigidity under $20 \cdot 10^{-6} \mathrm{Nm}$ and shear resistance lower than $10 \mathrm{~N} / \mathrm{m}$ will produce identical drape appearance and the pattern maker should concentrate more on the avatar dimension and pattern construction as on the parameters of the fabrics. Increasing the bending rigidity over $50 \cdot 10^{-6} \mathrm{Nm}$ produces slightly stiffer appearance, but does not change significantly the appearance of the style, defined by the pattern. This does not allow concluding that the exact material parameters are not important at all, but confirms the statement that for materials within the same application area the sensitivity of the modern CAD simulation tools for free style clothing is not high enough to feel the differences in static body postures. For close-to-the-body clothing and evaluation of the dynamic fit with fabric deformations, using more parameters and their exact values remains very important.

\section{Acknowledgements}

The authors would like to thank German Academic Exchange Service (DAAD) for funding the EECBP Home Grown PhD Scholarship Program 2019 (57472170) of Tibifez Hailu Nechno.

\section{References}

[1] Clothing and Appearance | Encyclopedia.com. Available online: https://www.encyclopedia.com/history/newswires-white-papers-and-books/clothing-and-appearance (accessed on June 12, 2020).

[2] Lage, A. and Ancutiene, K. 2017. Virtual try-on technologies in the clothing industry. Part 1: investigation of distance ease between body and garment. The Journal of The Textile Institute 108, 10, 1787-1793. DOI: https://doi.org/10.1080/00405000.2017.1286701.

[3] Sayem, A. S. M.; Kennon, R.; Clarke, N. 2010. 3D CAD systems for the clothing industry. International Journal of Fashion Design, Technology and Education 3, 45-53. DOI: https://doi.org/10.1080/17543261003689888.

[4] Liu, Y.-J.; Zhang, D.-L.; Yuen, M. M.-F. 2010. A survey on CAD methods in 3D garment design. Computers in Industry 61, 6, 576-593. DOI: https://doi.org/10.1016/j.compind.2010.03.007.

[5] Liu, K. X; Zeng, X. Y.; Bruniaux, P.; Wang, J. P.; Kamalha, E.; Tao, X. Y. 2017. Fit evaluation of virtual garment try-on by learning from digital pressure data. Knowledge-Based Systems 133, 174-182. DOI: https://doi.org/10.1016/j.knosys.2017.07.007. 
[6] Büyükaslan, E.; Jevsnik, S.; Kalaoglu, F. 2015. Virtual fitting of a skirt on a parametric and a scanned body model. Marmara Journal of Pure and Applied Sciences 27, 23-26. DOI: https://doi.org/10.7240/mufbed.52347.

[7] Assyst - Products - 3D Vidya. Available online: https://www.assyst.de/en/products/3d-vidya/index.html (accessed on September 20, 2021).

[8] [CLO/3D] Introduction to CLO - A 3D CAD Tool for the Apparel Business - How to Install | STYLY. Available online: https://styly.cc/tips/clo awai install/ (accessed on August 16, 2020).

[9] Hong, Y.; Bruniaux, P.; Zhang, J. J.; Liu, K. X.; Dong, M.; Chen, Y. 2018. Application of 3D-TO-2D garment design for a typical morphology: a design case for physically disabled people with scoliosis. Industria Textila 69, 1, 59-64. DOI: https://doi.org/10.35530/IT.069.01.1377.

[10] VStitcher 3D Apparel Design Software. Available online: https://browzwear.com/products/v-stitcher/ (accessed on August 18, 2020).

[11] Jevsnik, S.; Stjepanovic, Z.; Rudolf, A. 2017. 3D virtual prototyping of garments: approaches, eevelopments and challenges. Journal of Fiber Bioengineering and Informatics 10, 51-63. DOI: https://doi.org/10.3993/jfbim00253.

[12] Ögülmüş, E.; Üreyen, M. E.; Arslan, C. 2015. Comparison of real garment design and 3d virtual prototyping. Proc. of $15^{\text {th }}$ AUTEX World Textile Conference 2015, June 10-12, 2015, Bucharest, Romania.

[13] Bias, R.G.; Larson, K.; Huang, S.-C.; Aumer-Ryan, P. R.; Montesclaros, C. 2010. An exploratory study of visual and psychological correlates of preference for onscreen subpixel-rendered text. Journal of the American Society for Information Science and Technology 61, 4, 745-757. DOI: https://doi.org/10.1002/asi.21273.

[14] Kyosev, Y. Material description in the simulative 3D textile products development: data structure, open data exchange formats and system for automatic analysis of experimental series, Textile Research Journal, in Printing (11.2021), Online First, https://doi.org/10.1177/00405175211061192.

[15] Cieśla, K.; Frydrych, I.; Krzywinski, S.; Kyosev, Y. 2020. Design workflow for virtual design of clothing for pregnant women. Communications in Development and Assembling of Textile Products 1, 2, 148-159. DOI: https://doi.org/10.25367/cdatp.2020.1.p148-159.

[16] Salopek Cubric, I.; Cubric, G.; Potocic Matkovic, V. M.; Pavko Cuden, A. 2021. The comfort of knitted fabrics: interaction of sportswear and athlete's body. Communications in Development and Assembling of Textile Products 2, 1, 70-79. DOI: https://doi.org/10.25367/cdatp.2021.2.p70-79.

[17] Jevsnik, S.; Kalaoglu, F.; Terliksiz, S.; Purgaj, J. 2014. Review of computer models for fabric simulation. Tekstilec. 57, 4, 300-314. DOI: https://doi.org/10.14502/Tekstilec2014.57.300-314.

[18] Xu, J.; Zhang, W. B.; Xiao, P. 2008. A study on impact factors of the distance eases between body and garment. 2008 9th International Conference on Computer-Aided Industrial Design and Conceptual Design, Beijing, China, Nov. 22-25, 2008, 201-205. DOI: https://doi.org/10.1109/CAIDCD.2008.4730551

[19] Wong, A. S. W.; Li, Y.; Zhang, X. 2004. Influence of fabric mechanical property on clothing dynamic pressure distribution and pressure comfort on tight-fit sportswear. Sen'i Gakkaishi 60, 10, 293-299. DOI: https://doi.org/10.2115/fiber.60.293.

[20]Dabolina, I.; Fomina, J.; Lapkovska, E.; Silina, L. 2020. Selected dynamic anthropometrics and body characteristics for posture corrector fit. Communications in Development and Assembling of Textile Products 1 , 2, 96-103. DOI: https://doi.org/10.25367/cdatp.2020.1.p96-103.

[21]Rödel, H.; Schenk, A.; Herzberg, C.; Krzywinski, S. 2001. Links between design, pattern development and fabric behaviours for clothes and technical textiles. International Journal of Clothing Science and Technology 13, 3/4, 217-227. DOI: https://doi.org/10.1108/EUM0000000005782.

[22] Hallett, C.; Johnston, A. Fabric for Fashion: The Swatch Book, Laurence King Publishing, London, UHK, 2016. 